\title{
Monomelic amyotrophy with proximal upper limb involvement: a case report
}

Eman Al-Ghawi ${ }^{1}$, Talal Al-Harbi ${ }^{2}$, Adnan Al-Sarawi ${ }^{2}$ and Mohamed Binfalah ${ }^{3^{*}}$

\begin{abstract}
Background: Monomelic amyotrophy is an uncommon, benign, unilateral disorder of the lower motor neurons, affecting predominantly the hand and forearm muscles. Proximal involvement of the arm and shoulder muscles is an unusual presentation that has been rarely reported in the literature.

Case presentation: A 28-year-old white man presented with insidious-onset, slowly progressive, unilateral weakness and atrophy of his left shoulder girdle and deltoid muscles. A neurological examination revealed weakness and atrophy in his left deltoid, infraspinatus and supraspinatus muscles. Electromyography demonstrated an active and chronic neurogenic pattern affecting his left C5 and C6 myotomes; magnetic resonance imaging of his cervical spine was normal. He did well with conservative treatment.

Conclusions: Upper limb proximal form of monomelic amyotrophy is a rare clinical entity with a wide differential diagnosis. Physicians, especially neurologists, should be familiar with this benign condition to avoid inappropriately labeling patients as having amyotrophic lateral sclerosis and other disorders with less favorable outcomes.
\end{abstract}

Keywords: Amyotrophic lateral sclerosis, Electromyography, Hirayama disease, Magnetic resonance imaging, Proximal monomelic amyotrophy

\section{Background}

Monomelic amyotrophy (MA), also known as Hirayama disease, is a rare, benign lower motor neuron disease. Hirayama et al. originally reported this clinical entity in 1959, and called it "juvenile muscular atrophy of unilateral upper extremity" [1]. This disease is characterized by muscle wasting and weakness, affecting predominantly the lower cervical myotomes [2]. It affects mostly young males in their teens and twenties. The disease is more prevalent in India, Japan, and other Asian countries, but many cases have been reported from other parts of the world as well [3-5]. One report from India found that MA comprises approximately $12.8 \%$ of lower motor neuron diseases [5].

We report the case of a patient with MA, who presented with symptoms and signs in his proximal upper limb, a location rarely described in this disease [5-7].

\footnotetext{
* Correspondence: mfalahmd@gmail.com

${ }^{3}$ University Medical Center, King Abdullah Medical City, P.O. Box 26671,

Adliya, Kingdom of Bahrain

Full list of author information is available at the end of the article
}

\section{Case presentation}

A 28-year-old, right-handed white man presented with insidious-onset, slowly progressive weakness and wasting of his left deltoid and shoulder girdle muscles for the last 5 years. Initially, he noticed difficulty with abducting his left arm and raising it above head level. The weakness progressed slowly over the first 3 years of initial symptoms, and then became static. He denied history of trauma, shoulder pain, or sensory symptoms, and he was not on any medications prior to development of symptoms.

A neurological examination demonstrated significant atrophy of his left deltoid, supraspinatus and infraspinatus muscles, with no fasciculations (Fig. 1). His muscle strength, (according to Medical Research Council) was 3 in his deltoid, supraspinatus and infraspinatus muscles, $4+$ in his biceps and teres major, and 5 in other muscles. Deep tendon reflexes and sensory examination were normal. There were no upper motor neuron signs.

Nerve conduction studies (NCS) of his left upper limb were normal. Electromyography (EMG) revealed fasciculations and fibrillation potentials in his biceps, deltoid and supraspinatus. Large, polyphasic motor unit action 


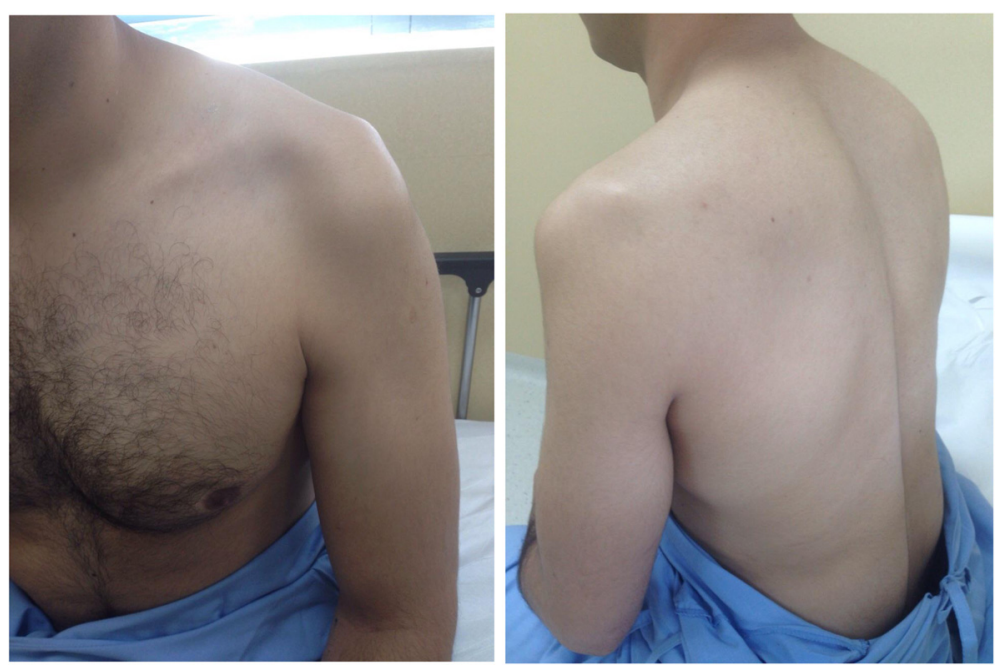

Fig. 1 Left shoulder photograph. Atrophy of the deltoid, supraspinatus and infraspinatus muscles

potentials with prolonged duration and reduced recruitment pattern were seen in the same muscles; the infraspinatus could not be tested due to severe degree of atrophy. EMG of other muscles in his upper and lower extremities, as well as cervical paraspinal muscles, was normal.

Blood investigations, including complete blood count, sedimentation rate, renal, liver and thyroid function tests, creatine kinase (CK), and vitamins. B12 and D3 were normal. There were negative results for vasculitis screening (rheumatoid factor, antinuclear antibody, extractable nuclear antigens, antiphospholipid antibody) and viral serology: human immunodeficiency virus (HIV), hepatitis B and C. Magnetic resonance imaging (MRI) of his cervical spine, done in the neutral position, was normal (Fig. 2), but a flexion-position MRI was not done.

He was diagnosed to have an upper limb proximal form of benign MA. He was prescribed a regular physiotherapy program to strengthen his shoulder muscles and improve range of movement. His muscle strength and functions have remained stable over the past 2 years. $\mathrm{He}$ is currently working as a clerk, with no functional limitations due to his illness. He is doing regular exercises given by his physiotherapist on a daily basis.

\section{Discussion}

MA, or Hirayama disease, is a rare benign disorder of the lower motor neurons. This condition was initially reported by Hirayama et al. in 1959 [1]; they called it "juvenile muscular atrophy of unilateral upper extremity". The disease is more prevalent in India, Japan, and other Asian countries, but many similar cases have been reported from other parts of the world as well [3-5]. For instance, one report from India found that MA comprises approximately $12.8 \%$ of lower motor neuron diseases [5]. To the best of our knowledge, this is the first case reported from our region (Arabian Gulf).

MA is characterized by insidious-onset, asymmetric, unilateral weakness and atrophy of the hand and forearm muscles, with sparing of the brachioradialis, giving rise to an appearance called 'oblique amyotrophy' $[1,8,9]$. Several case series have described predominant lower limb involvement $[4,10]$.

MA typically affects males between the ages of 15 and 25 years [9], but it can occur in females as well $[4,11]$. The disease progresses slowly over several years, before reaching a stationary stage $[3,9]$. Bilateral, usually

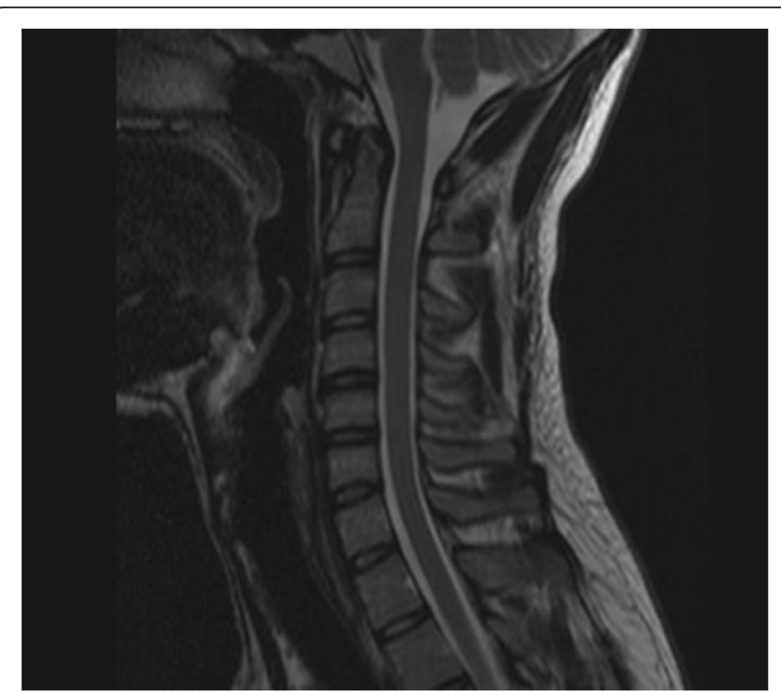

Fig. 2 Cervical spine magnetic resonance imaging (1.5 Tesla). Sagittal T2 section, demonstrating normal spinal cord and dural canal in the neutral position 
asymmetric, but also symmetric, 'bimelic' forms affecting the upper limbs have been observed [3].

Our patient presented with an uncommon form of MA, affecting the shoulder and arm muscles instead of the commonly seen hand and forearm disease. Rare cases of proximal upper limb MA have been reported in the literature [4-7]. De Freitas and Nascimento [4] studied 21 cases of MA involving the upper or lower extremities. Only one patient had proximal unilateral upper limb involvement; his MRI cervical spine and NCS were normal, while EMG revealed denervation in the affected muscles, similar to our patient. Another study [2] described 102 patients with MA. Only five of them had predominantly unilateral shoulder girdle weakness; however, EMG showed evidence of denervation not only in C5 and 6 myotomes, but also C 8 and T1 muscles, albeit to a lesser degree, denoting a more extensive disease, which was not seen in our patient.

Our patient did not have sensory symptoms or upper motor neuron signs during 5 years, or clinical or electrophysiological evidence for a widespread disease in bulbar or other limb muscles, indicating the benign nature of this condition.

Other characteristic clinical findings compatible with MA include course irregular tremor (polyminimyoclonus) of the fingers in affected hand, exaggeration of weakness on exposure to cold (cold paresis), and absence of sensory loss, pyramidal, cerebellar, cranial nerves, and sphincter deficits $[9,10,12]$.

The differential diagnosis of MA includes the distal form of spinal muscular atrophy, amyotrophic lateral sclerosis (ALS), post-polio syndrome, multifocal motor neuropathy with conduction block (MMNCB), as well as structural lesions of the cervical cord. These clinical entities can be identified by specific clinical, radiological and electrophysiological features.

The pathophysiology of MA remains unknown [4], but several postulations have been considered, such as viral infections, ischemia to anterior horn cells, and atopy [6, 9]. In 1987, Kikuchi et al. first proposed that a tight dural canal may be an underlying predisposing factor [13]. Hirayama [9] suggested a model of focal venous ischemia due to compression and flattening of the lower cervical cord arising from forward displacement of the cervical dural sac and spinal cord, caused by recurrent neck flexion.

MRI findings in MA are conflicting, with some studies showing localized asymmetric spinal cord atrophy, prominence and enhancement of posterior epidural venous plexus, and anterior shifting of posterior dural sac on flexion [14]. In one case series, more than $90 \%$ of patients were found to have several characteristic MRI abnormalities on flexion study, such as loss of dural attachment, anterior displacement of dorsal dura, and enhancing epidural crescent [12]. Other studies have demonstrated no MRI differences in the anterior-posterior cord diameter between patients and controls $[9,15]$.

An autopsy study on a patient with MA noticed anterior horn cell shrinkage and necrosis, various degrees of degeneration of small and large nerve cells, mild gliosis, and some circulatory insufficiency in the territory of the spinal cord. These abnormalities extended from C5 to T1 levels but were more marked at C7 and C8 [10].

Electrophysiological studies (NCS and EMG) are an essential part of the diagnostic process, showing mostly chronic denervation changes in affected muscles, with or without acute denervation potentials (fasciculations, positive sharp waves and fibrillations potentials). These studies are also helpful in excluding other apparently similar conditions (e.g. ALS, MMNCB, brachial plexopathy). Milder denervation changes can be seen in clinically unaffected muscles as well [4].

There is no consensus on the treatment of MA, but the use of cervical collar therapy during the acute progressive stage of the disease has been advocated [12]. The role of surgery in patients who progress despite conservative treatment is controversial, but duraplasty, anterior cervical decompression, and reconstruction with tendon transfers have yielded encouraging results in some patients [11]. Physiotherapy is helpful in preventing complications resulting from immobility such as joint stiffness and muscle wasting.

\section{Conclusions}

MA should be suspected in patients presenting with slowly progressive weakness and atrophy restricted to one limb, followed by a static phase. While most reported cases involve the lower cervical myotomes, affecting the hand and forearm muscles, proximal upper limb involvement can be seen rarely. EMG and MRI studies are helpful in confirming the diagnosis and ruling out other clinical entities presenting in a similar fashion. Treatment is conservative in most patients, with the use of a cervical collar in appropriate cases, and physiotherapy.

\section{Consent}

Written informed consent was obtained from the patient for publication of this case report and accompanying images. A copy of the written consent is available for review by the Editor-in-Chief of the journal.

\section{Abbreviations}

ALS: Amyotrophic lateral sclerosis; CK: Creatine kinase; EMG: Electromyography; HIV: Human immunodeficiency virus;

MA: Monomelic amyotrophy; MMNCB: Multifocal motor neuropathy with conduction block; MRI: Magnetic resonance imaging; NCS: Nerve conduction studies. 


\section{Competing interests}

The authors declare that they have no competing interests.

\section{Authors' contributions}

EA carried out the research project (design, organization and execution) and wrote the initial draft. MB acquired the data, performed the EMG, and contributed to writing the manuscript. TA and AA reviewed and critiqued the manuscript. All authors read and approved the final manuscript.

\section{Authors' information}

Eman Al-Ghawi is a consultant family physician, specialist in medical education, and senior family medicine tutor.

Talal Al-Harbi is a consultant neurologist and specialist in neuromuscular and neurometabolic disorders.

Adnan Al-Sarawi is a consultant neurologist, neuromuscular specialist, and epileptologist.

Mohamed Binfalah is a consultant neurologist and specialist in neuromuscular disorders.

\section{Acknowledgements}

We would like to thank Mitchelle Erika Cera and Karen Agbuya for helping with the figures in this manuscript.

\section{Author details}

${ }^{1}$ Ministry of Health, Building 1228, Road 4025, Juffair 340, Kingdom of Bahrain. ${ }^{2}$ Department of Neurology, King Fahad Specialist Hospital-Dammam, 6830 Ammar bin Thabit St, Al Muraikabat, Dammam 32253-3202, Saudi Arabia. ${ }^{3}$ University Medical Center, King Abdullah Medical City, P.O. Box 26671, Adliya, Kingdom of Bahrain.

Received: 13 June 2015 Accepted: 19 February 2016

Published online: 17 March 2016

\section{References}

1. Hirayama K, Toyokura Y, Tsubaki T. Juvenile muscular atrophy of unilateral upper extremity: a new clinical entity. Psychiatry Neurol Jpn. 1959:61:2190-7.

2. Peiris JB, Seneviratne KN, Wickremasinghe HR, Gunatilake SB, Gamage R. Non familial juvenile distal spinal muscular atrophy of upper extremity. J Neurol Neurosurg Psychiatry. 1989;52:314-9.

3. Pradhan S. Bilaterally symmetric form of Hirayama disease. Neurology. 2009:72:2083-9.

4. De Freitas MR, Nascimento OJ. Benign monomelic amyotrophy: a study of twenty-one cases. Arq Neuropsiquiatr. 2000:58:808-13.

5. Neves MA, Freitas MR, Mello MP, Dumard CH, Freitas GR, Nascimento OJ. Benign monomelic amyotrophy with proximal upper limb involvement. Arq Neuropsiquiatr. 2007;65:524-7.

6. Orsini M, Freitas MR, Catharino A, Mello MP, Nascimento OJ. Upper limb proximal form of monomelic amyotrophy: on purpose of 2 cases. Rev Bras Neurol. 2008:44:13-7.

7. Yilmaz O, Alemdaroğlu I, Karaduman A, Haliloğlu G, Topaloğlu H. Benign monomelic amyotrophy in a 7-year-old girl with proximal upper limb involvement: case report. Turk J Pediatr. 2011;53:471-6.

8. Talbot K. Monomelic amyotrophy or Hirayama's disease. Pract Neurol. 2004:4:362-5.

9. Hirayama K. Juvenile muscular atrophy of unilateral upper extremity (Hirayama disease): half-century progress and establishment since its discovery. Brain Nerve. 2008;60:17-29.

10. Hirayama K, Tomonaga M, Kitano K, Yamada T, Kojima S, Arai K. Focal cervical poliopathy causing juvenile muscular atrophy of distal upper extremity: a pathological study. J Neurol Neurosurg Psychiatry. 1987;50:285-90

11. Gourie-Devie M, Suresh TG, Shankar SK. Monomelic amyotrophy. Arch Neurol. 1984:41:388-94.

12. Hassan KM, Sahni H, Jha A. Clinical and radiological profile of Hirayama disease: a flexion myelopathy due to tight cervical dural canal amenable to collar therapy. Ann Indian Acad Neurol. 2012;15:106-12.

13. Kikuchi S, Tashiro K, Kitagawa M, Iwasaki Y, Abe H. A mechanism of juvenile muscular atrophy localized in the hand and forearm (Hirayama's disease): flexion myelopathy with tight dural canal in flexion [in Japanese]. Rinsho Shinkeigaku. 1987;27:412-9.
14. Harding AE, Bradbury PG, Murray NM. Chronic asymmetrical spinal muscular atrophy. J Neurol Sci. 1983;59:69-83.

15. Willeit J, Kiechl S, Kiechl-Kohlendorfer U, Golaszewski S, Peer S, Poewe W. Juvenile asymmetric segmental spinal muscular atrophy (Hirayama's disease): three cases without evidence of "flexion myelopathy". Acta Neurol Scand. 2001;104:320-2.

\section{Submit your next manuscript to BioMed Central and we will help you at every step:}

- We accept pre-submission inquiries

- Our selector tool helps you to find the most relevant journal

- We provide round the clock customer support

- Convenient online submission

- Thorough peer review

- Inclusion in PubMed and all major indexing services

- Maximum visibility for your research

Submit your manuscript at www.biomedcentral.com/submit 